\title{
BRAF V600E and risk stratification of thyroid microcarcinoma: a multicenter pathological and clinical study
}

Giovanni Tallini ${ }^{1,14}$, Dario de Biase ${ }^{1,14}$, Cosimo Durante ${ }^{2,14}$, Giorgia Acquaviva ${ }^{1}$, Michele Bisceglia ${ }^{3}$, Rocco Bruno ${ }^{4}$, Maria Letizia Bacchi Reggiani ${ }^{5}$, Gian Piero Casadei ${ }^{6}$, Giuseppe Costante ${ }^{7}$, Nadia Cremonini ${ }^{8}$, Livia Lamartina ${ }^{2}$, Domenico Meringolo ${ }^{9}$, Francesco Nardi ${ }^{10}$, Annalisa Pession ${ }^{11}$, Kerry J Rhoden ${ }^{12}$, Giuseppe Ronga ${ }^{2}$,

Massimo Torlontano ${ }^{13}$, Antonella Verrienti ${ }^{2}$, Michela Visani ${ }^{11}$ and Sebastiano Filetti ${ }^{2}$

${ }^{1}$ Department of Medicine (DIMES), Anatomic Pathology Unit, Bellaria Hospital, University of Bologna School of Medicine, Bologna, Italy; ${ }^{2}$ Department of Internal Medicine and Medical Specialties, University 'Sapienza', Rome, Italy; ${ }^{3}$ Anatomic Pathology Unit, School of Biomedical Sciences, Etromapmacs Pole, Lesina, Italy; ${ }^{4}$ Endocrinology Unit, Tinchi-Pisticci Hospital, Matera, Italy; ${ }^{5}$ Department of Medicine (DIMES), Cardiology Unit, University of Bologna, Bologna, Italy; ${ }^{6}$ Anatomic Pathology Unit, AUSL Bologna-Maggiore Hospital, Bologna, Italy; ${ }^{7}$ Department of Health Science, University Magna Grecia di Catanzaro, Catanzaro, Italy; ${ }^{8}$ Endocrinology Unit, AUSL Bologna-Maggiore Hospital, Bologna, Italy; ${ }^{9}$ Endocrinology Unit, AUSL BolognaBentivoglio Hospital, Bologna, Italy; ${ }^{10}$ Department of Experimental Medicine, Anatomic Pathology Unit, University 'Sapienza', Rome, Italy; ${ }^{11}$ Department of Pharmacology and Biotechnology (FaBiT), University of Bologna, Bologna, Italy; ${ }^{12}$ Department of Medicine (DIMEC), Medical Genetics Unit, University of Bologna, Bologna, Italy and ${ }^{13}$ Department of Medical Science, Ospedale Casa Sollievo della Sofferenza-IRCCS, San Giovanni Rotondo, Italy

Studies from single institutions have analyzed $B R A F$ in papillary microcarcinomas, sometimes with contradictory results. Most of them have provided limited integration of histological and clinical data. To obtain a comprehensive picture of BRAF V600E-mutated microcarcinomas and to evaluate the role of BRAF testing in risk stratification we performed a retrospective multicenter analysis integrating microscopical, pathological, and clinical information. Three hundred and sixty-five samples from 300 patients treated at six medical institutions covering different geographical regions of Italy were analyzed with central review of all cases. BRAF V600E statistical analysis was conducted on 298 microcarcinomas from 264 patients after exclusion of those that did not meet the required criteria. BRAF V600E was identified in $145 / 298$ tumors (49\%) including the following subtypes: $35 / 37$ (95\%, $\boldsymbol{P}<0.0001)$ tall cell and $72 / 114(64 \%, P<0.0001)$ classic; conversely $94 / 129$ follicular variant papillary microcarcinomas $(73 \%, P<0.0001)$ were $B R A F$ wild type. BRAF V600E-mutated microcarcinomas were characterized by markedly infiltrative contours $(P<0.0001)$ with elongated strings of neoplastic cells departing from the tumor, and by intraglandular tumor spread $(P<0.0001)$, typically within $5 \mathrm{~mm}$ of the tumor border. Multivariate analysis correlated BRAF V600E with specific microscopic features (nuclear grooves, optically clear nuclei, tall cells within the tumor, and tumor fibrosis), aggressive growth pattern (infiltrative tumor border, extension into extrathyroidal tissues, and intraglandular tumor spread), higher American Thyroid Association recurrence risk group, and non-incidental tumor discovery. The following showed the strongest link to BRAF V600E: tall cell subtype, many neoplastic cells with nuclear grooves or with optically clear nuclei, infiltrative growth, intraglandular tumor spread, and a tumor discovery that was non-incidental. BRAF V600E-mutated microcarcinomas represent a distinct biological subtype. The mutation is associated with conventional clinico-pathological features considered to be adverse prognostic factors for papillary microcarcinoma, for which it could be regarded as a surrogate marker. BRAF analysis may be useful to identify tumors (BRAF wild type) that have negligible clinical risk. Modern Pathology (2015) 28, 1343-1359; doi:10.1038/modpathol.2015.92; published online 14 August 2015

Correspondence: G Tallini, MD, Department of Medicine (DIMES), Anatomic Pathology Unit, Bellaria Hospital, University of Bologna School of Medicine, Via Altura 3, Bologna 40139, Italy.

E-mail: giovanni.tallini@unibo.it

${ }^{14}$ These authors contributed equally to this work.

Received 21 April 2015; revised 11 June 2015; accepted 15 June 2015; published online 14 August 2015 
Papillary microcarcinoma is traditionally defined as a papillary thyroid carcinoma measuring $1 \mathrm{~cm}$ or less. Many autopsy studies over the years have shown that small papillary carcinomas are a common finding in humans, supporting the existence of a subgroup of papillary cancers that are biologically of very low malignant potential and clinically 'dormant'. A meta-analysis reviewing 1000 such cases from 15 autopsy series from different world regions found an overall prevalence for papillary microcarcinoma of $11.5 \% .^{1}$ This prevalence is compatible with the $12-13 \%$ rate for microcarcinomas diagnosed incidentally in thyroid glands surgically removed for goiter or other reasons. ${ }^{2}$

The advent of preoperative fine needle aspiration biopsies and the widespread utilization of imaging techniques have allowed the identification of a progressively larger number of small papillary carcinomas. $^{3,4}$ Some of these small cancers are presumably those endowed with only a very limited malignant potential found in autopsy series, and a sensible proposal to re-name papillary thyroid microcarcinoma 'papillary microtumor' (instead of 'microcarcinoma'), has been made for cases where the neoplastic focus is single, entirely contained within the thyroid gland, and found incidentally in a patient older than 18 years. ${ }^{5}$ Other microcarcinomas, however, are simply small tumors with the potential to progress. As they are low stage, the large majority have an excellent prognosis, but $\sim 25 \%$ of cases are at risk of persistent/recurrent disease. ${ }^{6}$

Conventional staging criteria do not necessarily predict an unfavorable outcome in patients with thyroid microcarcinomas. In a large meta-analysis ${ }^{7}$ the size of the microcarcinoma, the presence of extrathyroidal extension, or the sex of the patient were not associated with tumor recurrence. The presence of distant metastases at the time of diagnosis resulted in persistent disease in some of the patients, but was not statistically associated with the development of new metastases during followup. On the other hand, recurrent disease was independently associated with tumors that were clinically evident, multifocal within the gland, or with lymph node involvement at the time of diagnosis. ${ }^{7}$ Younger, as opposed to older age, was independently associated with recurrent disease. ${ }^{7}$ Large metastatic lymph nodes harboring foci of poorly differentiated carcinoma have been consistently associated with tumor recurrence and even patient death, ${ }^{8,9}$ but little is generally known about the histological features of the microcarcinomas that are associated with tumor recurrence or unfavorable prognosis. Not surprisingly, the management of papillary microcarcinoma is debated and there is a need to identify those microcarcinoma patients who are exposed to potential clinical risk.

The BRAF V600E mutation represents a very specific marker for papillary thyroid carcinoma and a remarkable body of evidence has linked the mutation to aggressive features and loss of differen- tiation. ${ }^{10-15}$ Several studies have associated $B R A F$ V600E with prognostic factors generally related to aggressive behavior $^{16-19}$ and with persistent disease ${ }^{20}$ in patients with microcarcinoma. In other studies however, the mutation did not correlate with adverse prognostic features. ${ }^{21-24}$ Some of the discrepancies, common also to studies analyzing $B R A F$ mutation in tumors larger than $1 \mathrm{~cm}$, may reflect the selection of cases, mutation detection procedures, geographic variation (even within the same country), ${ }^{17,21,25}$ or the lack of integration between mutation analysis and tumor histotype/growth features. ${ }^{26}$

The studies that have analyzed the BRAF V600E mutation in thyroid microcarcinomas have been based on single institutions, and have usually provided very limited integration of $B R A F$ mutation results with clinicopathological data and histological features. We report the findings of a systematic analysis of the microscopic characteristics, growth pattern, and clinical properties of $B R A F$ V600Emutated tumors $<1 \mathrm{~cm}$ in a multicenter study large enough to draw relevant conclusions on the biological and clinical significance of the BRAF V600E mutation in papillary thyroid microcarcinoma.

\section{Materials and methods}

\section{Study Group and Inclusion Criteria}

See Supplementary Materials and Methods. Microcarcinomas from six medical institutions covering different geographical areas of Italy (Bellaria and Maggiore Hospitals in Bologna-North; University Hospital-Università 'Sapienza' in Rome-Center; Casa Sollievo della Sofferenza Hospital in San Giovanni Rotondo-South, the city Hospitals of Matera and Catanzaro-South) were subjected to central review of histology slides, and of all pathological and clinical data. The study was approved by the ethics committee of the Università 'Sapienza' in Rome on behalf of all the centers.

\section{Pathological and Clinical Data}

Tumor subtype. Defined according to the World Health Organization (2004) criteria used for tumors $>1 \mathrm{~cm}$. See Table 1 and Supplementary Materials and Methods.

Microscopic appearance of the tumor. See Supplementary Materials and Methods for the definition of the variables analyzed in Table 2 .

Extent and type of tumor growth. See Supplementary Materials and Methods for the definition of the variables analyzed in Table 3. Intraglandular tumor spread was defined as the presence of neoplastic cell aggregates separated from a principal tumor mass by at least one layer of non-neoplastic thyroid. For the purpose of this study, tumor multicentricity was 


\begin{tabular}{|c|c|c|c|}
\hline & \multicolumn{2}{|c|}{$B R A F$} & \multirow{2}{*}{$\frac{\text { Univariate analysis }}{\mathrm{P} \text {-value }}$} \\
\hline & $\operatorname{V600E}(\%)$ & $W T(\%)$ & \\
\hline Papillary microcarcinomas & $145 / 298(49)$ & $153 / 298(51)$ & \\
\hline Classic $(n=114)$ & $72 / 145(50)$ & $42 / 153(27)$ & $<0.0001$ \\
\hline Follicular variant $(n=129)$ & $35 / 145(24)$ & $94 / 153(61)$ & $<\mathbf{0 . 0 0 0 1}$ \\
\hline Tall cell $(n=37)$ & $35 / 145(24)$ & $2 / 153(1)$ & $<0.0001$ \\
\hline Solid trabecular $(n=8)$ & $1 / 145(1)$ & $7 / 153(5)$ & 0.0674 \\
\hline Other $(n=10)$ & 2/145 (1) & $8 / 153(5)$ & 0.1047 \\
\hline
\end{tabular}

Abbreviations: V600E, BRAF V600E-mutated tumors; WT, BRAF wild-type tumors.

In bold $P<0.05$; in italics $0.05<P<0.1$.

Data based on 298 papillary microcarcinomas.

defined as the presence of at least two separate tumor foci of similar dimensions, irrespective of the histological appearance of the tumor, or the presence of at least two separate tumor foci of different histological appearance, regardless of their diameter. Since, according to the above definition, multicentric thyroid microcarcinomas may represent synchronous independent tumors, multicentric microcarcinoma foci were analyzed separately.

Clinical data. See Supplementary Materials and Methods for the definition of the variables analyzed in Table 4. Stage was defined according to current criteria (American Joint Committee on Cancer, 2010). Patients were retrospectively assigned to low or intermediate recurrence risk groups following American Thyroid Association criteria (2009). Unfavorable tumor-related events were classified as persistent disease (documented within 1 year of the diagnosis), and recurrent disease (documented 1 year after the diagnosis).

\section{BRAF V600E Mutation Analysis}

See Supplementary Materials and Methods. Mutation analysis was performed using Allele Specific Locked Nucleic Acid PCR. ${ }^{27}$

\section{Immunohistochemistry}

See Supplementary Materials and Methods. Immunohistochemistry for cytokeratin 19, CD31, CD34, and Popodoplanin (D2-40 antibody) was performed according to previously published protocols. ${ }^{28}$

\section{Statistical Analysis}

See Supplementary Materials and Methods.

\section{Results}

To obtain a comprehensive picture of BRAF V600Emutated thyroid microcarcinomas we studied 365 tumor samples from 300 patients from different
Italian regions with central review and meticulous histological analysis of each case. After exclusion of those that did not meet the required criteria $B R A F$ V600E statistical analysis was conducted on 298 microcarcinomas from 264 patients, 191 of them with detailed follow-up.

The original selection of cases from the six medical institutions participating in the study included 365 tumor samples from 300 patients. In 28 cases the amount of residual tumor material on the paraffin block was too scant and all were excluded from DNA analysis. Therefore, a total of 337 samples from 276 patients were tested for $B R A F$ V600E. Eighteen additional samples were excluded: 6 cases due to lack of amplifiable DNA, 12 cases because the diagnosis of microcarcinoma could not be confirmed after histological review. Of these 12 cases, 3 were $>1 \mathrm{~cm}$ after measuring the tumor diameter on the H\&E slide, whereas in the remaining 9 cases the diagnosis was revised after microscopic examination of the histology sections. The revised histological diagnoses were follicular foci with nuclear clearing within an adenomatous nodule (five cases), follicular foci with nuclear clearing in Hashimoto thyroiditis (one case), follicular tumor of undetermined malignant potential (two cases), and hyalinizing trabecular tumor (one case). The $B R A F$ V600E mutation was identified in one of the three cases $>1 \mathrm{~cm}$, and in none of the nine cases where the diagnosis was revised. The remaining 319 samples were obtained from 298 microcarcinomas, from 5 foci of intraglandular spread of neoplastic cells corresponding to 5 separate microcarcinomas and from 16 microcarcinoma lymph node metastases. In the five intraglandular tumor spread samples and the 16 lymph node metastases the results of BRAF V600E mutation analysis were consistent with that of the primary tumor.

Seventy-five of the 264 patients had multicentric microcarcinomas. In addition to the BRAF status of the largest tumor, that of additional microcarcinoma foci could be determined in a total of 34 tumors from 29 of the 75 patients with multicentric microcarcinomas. Twelve of the 34 multicentric microcarcinomas had divergent BRAF results in the 
Table 2 Microscopic appearance of papillary microcarcinoma and BRAF status

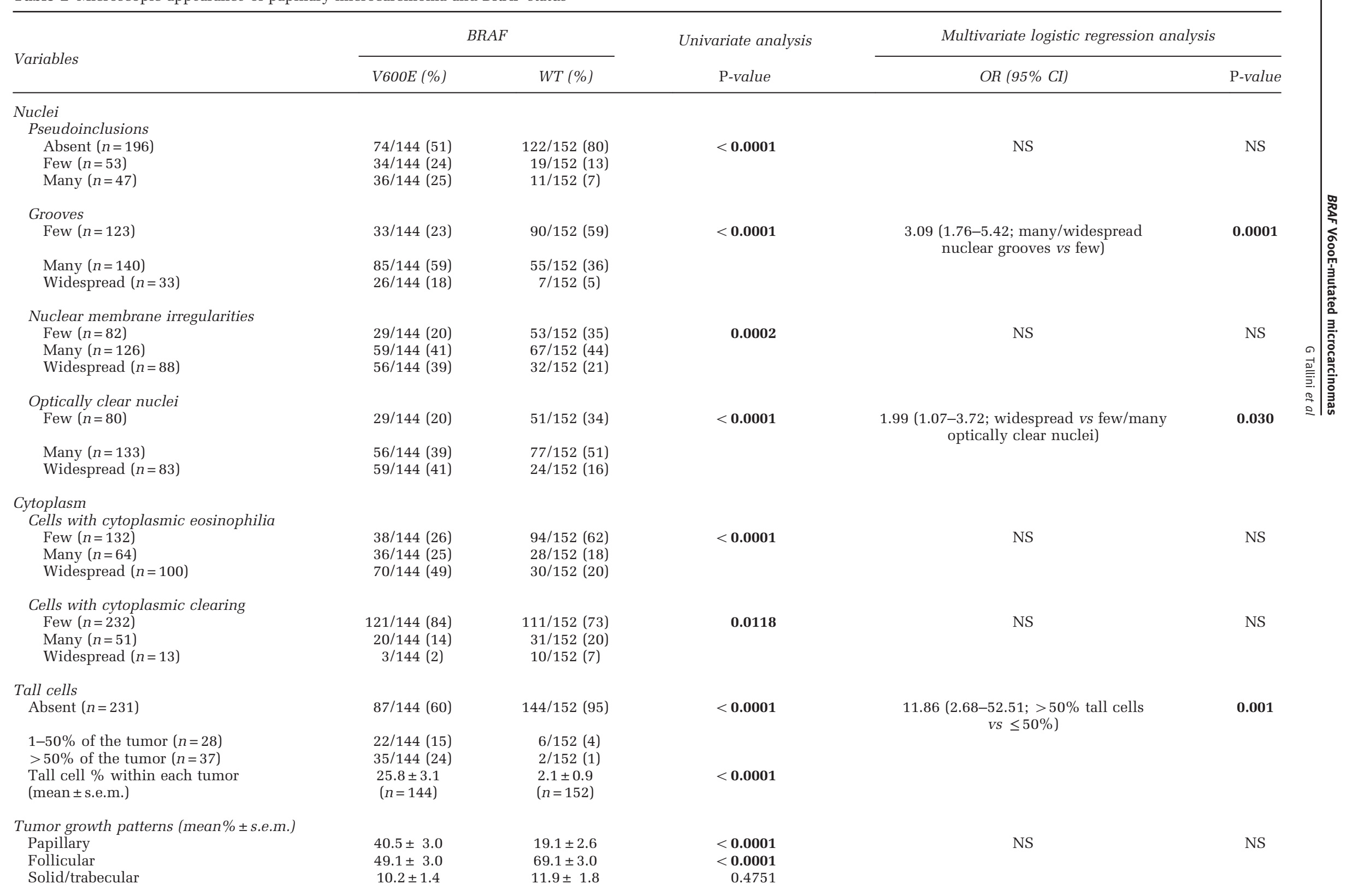




\begin{tabular}{|c|c|c|c|c|c|}
\hline \multirow{2}{*}{ Variables } & \multicolumn{2}{|c|}{ BRAF } & \multirow{2}{*}{$\begin{array}{l}\text { Univariate analysis } \\
\text { P-value }\end{array}$} & \multicolumn{2}{|c|}{ Multivariate logistic regression analysis } \\
\hline & $\operatorname{V600E}(\%)$ & $W T(\%)$ & & OR $(95 \%$ CI $)$ & P-value \\
\hline \multicolumn{6}{|c|}{ Fibrosis associated with the tumor } \\
\hline Absent $(n=154)$ & $55 / 144(38)$ & $99 / 152(65)$ & 0.0001 & $\begin{array}{c}1.79 \begin{array}{c}(1.04-3.10 ; \text { fibrosis present } \\
\text { Vs absent) }\end{array}\end{array}$ & 0.037 \\
\hline Mild $(n=59)$ & $40 / 144(28)$ & 19/152 (13) & & & \\
\hline Moderate/extensive $(n=83)$ & $49 / 144(34)$ & $34 / 152(22)$ & & & \\
\hline \multicolumn{6}{|l|}{ Mitoses } \\
\hline No $(n=243)$ & 113/144 (96) & 130/152 (99) & 0.1136 & & \\
\hline Yes $(n=53)$ & $31 / 144(4)$ & $22 / 152(1)$ & & & \\
\hline \multicolumn{6}{|l|}{ Tumor necrosis } \\
\hline No $(n=289)$ & 138/144 (96) & 151/152 (99) & 0.0471 & NS & NS \\
\hline Yes $(n=7)$ & $6 / 144(4)$ & $1 / 152(1)$ & & & \\
\hline \multicolumn{6}{|l|}{ Psammoma bodies } \\
\hline \multicolumn{6}{|l|}{ Within the microcarcinoma } \\
\hline Absent $(n=226)$ & $102 / 144(71)$ & 124/152 (82) & 0.0906 & & \\
\hline Few $(n=42)$ & 27/144 (19) & $15 / 152(10)$ & & & \\
\hline Many $(n=28)$ & $15 / 144(10)$ & $13 / 152(8)$ & & & \\
\hline \multicolumn{6}{|c|}{ In the non-neoplastic tissue surrounding the microcarcinoma } \\
\hline Absent $(n=266)$ & 125/144 (87) & 141/153 (92) & 0.2749 & & \\
\hline Few $(n=20)$ & 13/144 (9) & $7 / 153(5)$ & & & \\
\hline Many $(n=11)$ & $6 / 144(4)$ & $5 / 153(3)$ & & & \\
\hline \multicolumn{6}{|l|}{ Lymphoid cell infiltration } \\
\hline \multicolumn{6}{|l|}{ Within the microcarcinoma } \\
\hline Absent/scarce $(n=235)$ & $104 / 144(72)$ & $131 / 152(86)$ & 0.0033 & NS & NS \\
\hline Moderate $(n=44)$ & 28/144 (19) & 16/152 (11) & & & \\
\hline Diffuse $(n=17)$ & $12 / 144(8)$ & $5 / 152(3)$ & & & \\
\hline \multicolumn{6}{|c|}{ At the interface between the microcarcinoma and the surrounding non-neoplastic tissue } \\
\hline Absent/scarce $(n=157)$ & $54 / 143(38)$ & $103 / 153(67)$ & $<0.0001$ & 1.73 (1.00-3.02; moderate or diffuse & 0.051 \\
\hline Moderate $(n=83)$ & $50 / 143(35)$ & $33 / 153(22)$ & & & \\
\hline Diffuse $(n=56)$ & $39 / 143(27)$ & 17/153 (11) & & & \\
\hline
\end{tabular}

Abbreviations: NS, not significant $(P>0.1)$; OR, odds ratio; s.e.m., standard error of mean; V600E, BRAF V600E-mutated tumors; WT, BRAF WT tumors.

In bold $P<0.05$; in italics $0.05<P<0.1$.

Data based on 298 papillary microcarcinomas. 
Table 3 Extent and type of papillary microcarcinoma growth and BRAF status

\begin{tabular}{|c|c|c|c|c|c|}
\hline \multirow[b]{2}{*}{ Variables } & \multicolumn{2}{|c|}{$B R A F$} & \multirow{2}{*}{$\begin{array}{c}\begin{array}{c}\text { Univariate } \\
\text { analysis }\end{array} \\
\text { P-value }\end{array}$} & \multicolumn{2}{|l|}{ Multivariate logistic regression analysis } \\
\hline & $\operatorname{V600E}(\%)$ & $W T(\%)$ & & OR $(95 \% \mathrm{CI})$ & P-value \\
\hline \multicolumn{6}{|l|}{ Tumor size $(\mathrm{mm})^{\mathrm{a}}$} \\
\hline Tumor size $<5 \mathrm{~mm}(n=147)$ & $56 / 145(39)$ & $91 / 153(60)$ & $<0.0001$ & $\begin{array}{l}1.58(0.93-2.68 \text {; tumor size } \geq 5 \mathrm{~mm} \text { vs } \\
<5 \mathrm{~mm})\end{array}$ & 0.089 \\
\hline Tumor size $\geq 5 \mathrm{~mm}(n=151)$ & $89 / 145(61)$ & $62 / 153(40)$ & & & \\
\hline Mean \pm s.e.m. & $\begin{array}{l}5.9 \pm 0.2 \\
(n=145)\end{array}$ & $\begin{array}{l}4.5 \pm 0.2 \\
(n=153)\end{array}$ & $<0.0001$ & & \\
\hline \multicolumn{6}{|c|}{ Tumor growth pattern at the border with the surrounding non-neoplastic tissue } \\
\hline $\begin{array}{l}\text { Predominantly smooth/pushing } \\
(n=123)\end{array}$ & $41 / 144(29)$ & $82 / 153(54)$ & $<0.0001$ & $\begin{array}{l}2.24 \text { (1.22-4.12; predominantly irregular/ } \\
\text { infiltrative vs predominantly smooth/ } \\
\text { pushing or both pushing and infiltrative) }\end{array}$ & 0.010 \\
\hline $\begin{array}{l}\text { Both pushing and infiltrative } \\
(n=84)\end{array}$ & $39 / 144(27)$ & $45 / 153(29)$ & & & \\
\hline $\begin{array}{l}\text { Predominantly irregular/ } \\
\text { infiltrative }(n=90)\end{array}$ & $64 / 144(44)$ & 26/153 (17) & & & \\
\hline \multicolumn{6}{|l|}{ Invasion of extrathyroidal tissues } \\
\hline Absent $(n=229)$ & $94 / 145(65)$ & 135/153 (88) & $<0.0001$ & 2.06 (1.06-4.02; present vs absent) & 0.034 \\
\hline Minimal $(n=35)$ & 28/145 (19) & $7 / 153(5)$ & & & \\
\hline Conspicuous $(n=34)$ & 23/145 (16) & $11 / 153(7)$ & & & \\
\hline \multicolumn{6}{|l|}{ Vascular invasion } \\
\hline Absent $(n=280)$ & 130/144 (90) & 150/153 (98) & 0.0093 & NS & NS \\
\hline Single focus $(n=13)$ & 11/144 (8) & 2/153 (1) & & & \\
\hline Multiple foci $(n=4)$ & $3 / 144(2)$ & $1 / 153(1)$ & & & \\
\hline \multicolumn{6}{|l|}{ Microcarcinoma and IGTS } \\
\hline Absent (no IGTS foci; $n=184$ ) & $65 / 143(46)$ & 119/153 (78) & $<0.0001$ & 2.40 (1.37-4.21; present vs absent) & 0.002 \\
\hline Small ( 3 or less IGTS foci; $n=64$ ) & $46 / 143(32)$ & $18 / 153(12)$ & & & \\
\hline $\begin{array}{l}\text { Large ( } 4 \text { or more IGTS foci; } \\
n=48)\end{array}$ & $32 / 143(22)$ & 16/153 (10) & & & \\
\hline \multicolumn{6}{|l|}{ Microcarcinoma multicentric } \\
\hline No $(n=194)$ & 97/145 (67) & $97 / 153(63)$ & 0.6090 & & \\
\hline Yes $(n=104)$ & $48 / 145(33)$ & $56 / 153(37)$ & & & \\
\hline $\begin{array}{l}\text { Number of multicentric tumor } \\
\text { foci (mean } \pm \text { s.e.m.) }\end{array}$ & $\begin{array}{l}1.5 \pm 0.1 \\
(n=145)\end{array}$ & $\begin{array}{l}1.5 \pm 0.1 \\
(n=153)\end{array}$ & 0.9379 & & \\
\hline \multicolumn{6}{|l|}{ Tumor capsule } \\
\hline Absent $(n=194)$ & $109 / 144(76)$ & $110 / 153(72)$ & 0.2239 & & \\
\hline $\begin{array}{l}\text { Present without infitration } \\
(n=25)\end{array}$ & 8/144 (6) & 17/153 (11) & & & \\
\hline Present and infiltrated $(n=53)$ & $27 / 144(18)$ & 26/153 (17) & & & \\
\hline \multicolumn{6}{|l|}{ Cystic component } \\
\hline No $(n=277)$ & $132 / 144(92)$ & $145 / 153(95)$ & 0.4040 & & \\
\hline Yes $(n=20)$ & $12 / 144(8)$ & 8/153 (5) & & & \\
\hline \multicolumn{6}{|c|}{ Microcarcinoma developed within a larger hyperplastic nodule } \\
\hline No $(n=283)$ & $143 / 144(99)$ & 140/153 (92) & 0.0040 & $0.16(0.20-1.23)$ & 0.078 \\
\hline Yes $(n=14)$ & $1 / 144(1)$ & $13 / 153(8)$ & & & \\
\hline \multicolumn{6}{|l|}{ Surgical margins } \\
\hline Negative $(n=273)$ & 127/143 (89) & 146/153 (95) & 0.0684 & & \\
\hline Positive-focal infiltration $(n=15)$ & $11 / 143(8)$ & 4/153 (3) & & & \\
\hline $\begin{array}{l}\text { Positive-extensive infiltration } \\
(n=8)\end{array}$ & $5 / 143(3)$ & $3 / 153(2)$ & & & \\
\hline
\end{tabular}

Abbreviations: IGTS, intraglandular tumor spread; NS, not significant $(P>0.1)$; OR, odds ratio; s.e.m., standard error of mean; V600E, $B R A F$ V600Emutated tumors; WT, BRAF WT tumors.

$\mathrm{a}_{5} \mathrm{~mm}$ is the mean (and median) tumor size.

In bold $P<0.05$; in italics $0.05<P<0.1$.

Data based on 298 papillary microcarcinomas. 


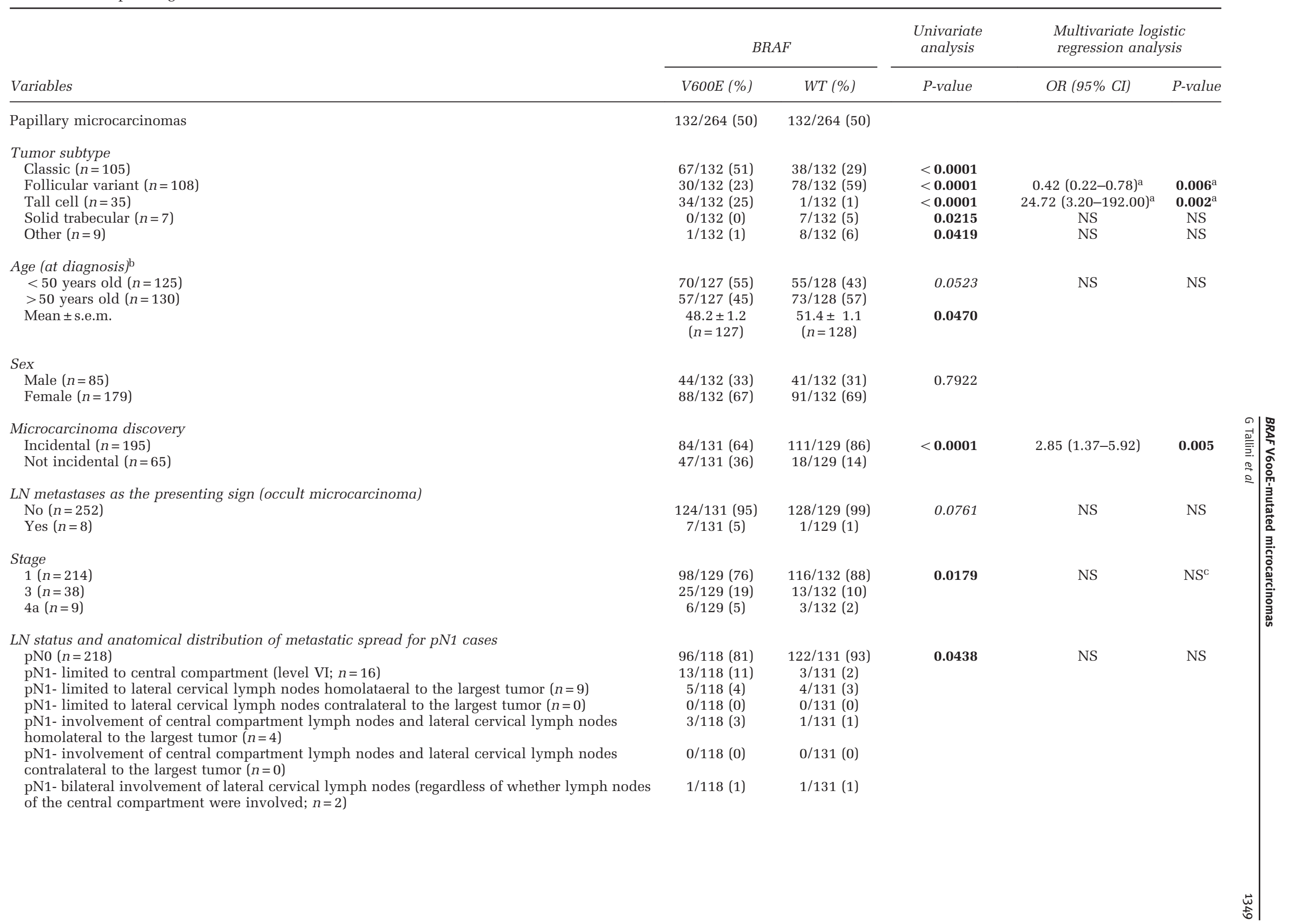




\section{Table 4 (Continued)}

\begin{tabular}{|c|c|c|c|c|c|}
\hline \multirow[b]{2}{*}{ Variables } & \multicolumn{2}{|c|}{$B R A F$} & \multirow{2}{*}{$\begin{array}{c}\begin{array}{c}\text { Univariate } \\
\text { analysis }\end{array} \\
P \text {-value }\end{array}$} & \multicolumn{2}{|c|}{$\begin{array}{l}\text { Multivariate logistic } \\
\text { regression analysis }\end{array}$} \\
\hline & V600E (\%) & $W T(\%)$ & & OR $(95 \%$ CI) & $P$-value \\
\hline \multicolumn{6}{|l|}{ ATA (2009) recurrence risk groups } \\
\hline Low $(n=184)$ & 75/132 (57) & 109/132 (83) & $<0.0001$ & $2.22(1.17-4.22)$ & $\mathbf{0 . 0 1 4 ^ { \mathrm { d } }}$ \\
\hline Intermediate $(n=80)$ & $57 / 132(43)$ & $23 / 132(17)$ & & & \\
\hline \multicolumn{6}{|l|}{ Administration of RAI } \\
\hline No $(n=160)$ & $83 / 129(64)$ & 77/132 (58) & 0.3847 & & \\
\hline Yes $(n=101)$ & $46 / 129(36)$ & $55 / 132(42)$ & & & \\
\hline \multicolumn{6}{|c|}{ Unfavorable disease-related patient events (persistent or recurrent disease) } \\
\hline No $(n=184)$ & $87 / 92(95)$ & 97/99 (98) & 0.2095 & & \\
\hline Yes $(n=7)$ & $5 / 92(5)$ & $2 / 99(2)$ & & & \\
\hline \multicolumn{6}{|c|}{ Non neoplastic thyroid disease co-existing with the microcarcinoma ${ }^{\mathrm{e}}$} \\
\hline \multicolumn{6}{|c|}{ Lymphocytic thyroiditis } \\
\hline Absent or focal $(n=262)$ & 133/144 (92) & 129/153 (84) & 0.0489 & NS & NS \\
\hline Diffuse $(n=35)$ & $11 / 144(8)$ & $24 / 153(16)$ & & & \\
\hline \multicolumn{6}{|l|}{ Nodular hyperplasia } \\
\hline Absent, few hyperplastic nodules $(n=171)$ & 94/144 (65) & 77/153 (50) & 0.0128 & NS & NS \\
\hline Numerous hyperplastic nodules, some > cm $1(n=126)$ & $50 / 144(35)$ & $76 / 153(50)$ & & & \\
\hline
\end{tabular}

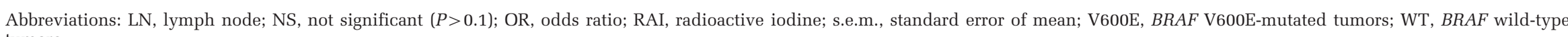
tumors.

${ }^{\mathrm{a}}$ For the multivariate analysis of tumor subtype categories OR and $P$-values have been calculated using the Classic subtype as the reference category.

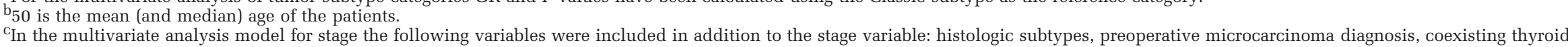

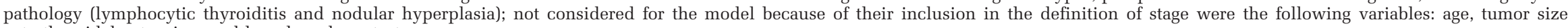
extrathyroidal extension, and lymph node metastases.

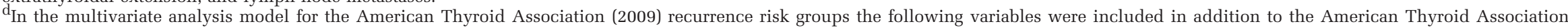

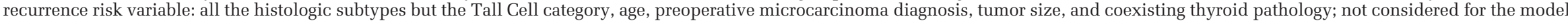

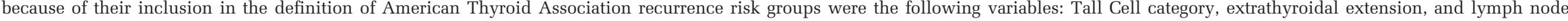
metastases.

${ }^{\text {e}}$ The presence of non-neoplastic thyroid disease was evaluated histologically.

$P>0.1$. In bold $P<0.05$; in italics $0.05<P<0.1$.

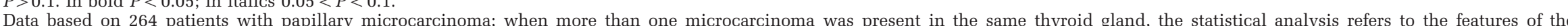
largest tumor. The statistical analysis for non neoplastic thyroid disease (thyroiditis, nodular hyperplasia) was based on the review of 297 microcarcinomas. 
different samples analyzed from the same thyroid gland, supporting the assumption that multicentric microcarcinomas, as defined in this study, represent indeed synchronous tumors that are most likely of independent origin ( $P=0.043$, McNemar's test).

Overall, BRAF V600E was identified in 145/298 tumors $(49 \%)$. The statistical relationship of $B R A F$ V600E with the histologic subtypes of the 298 microcarcinomas subjected to screening for BRAF mutation is summarized in Table 1, with their microscopic features in Table 2, and with the characteristics of the papillary thyroid microcarcinoma growth in Table 3.

Figure 1 illustrates the relationship of BRAF V600E with the microcarcinoma subtype (Figure 1a), the proportion of different growth patterns within the microcarcinoma (Figure 1b), the degree of intraglandular tumor spread (Figure 1c), and the geographical origin of the microcarcinomas (Figure 1d). Although there were differences in the BRAF V600E mutation prevalence in microcarcinomas from patients of different Italian regions these differences were not statistically significant $\left(P=0.1687, \chi^{2}\right.$ test). Figure 2 illustrates histopathological features that were associated with $B R A F$ V600E.

The statistical relationship after both univariate and multivariate analyses of $B R A F \mathrm{~V} 600 \mathrm{E}$ with the clinicopathological characteristics of the microcarcinoma in the 264 patients whose tumors were subjected to screening for BRAF mutation is summarized in Table 4. If more than one papillary thyroid microcarcinoma was present in the same thyroid gland (multicentric cases) the largest tumor was considered for statistical analysis.

Comprehensive multivariate study of all histopathological and clinical parameters with $P<0.1$ after multivariate analyses in Tables $1-4$, revealed the following features to be independently associated with BRAF V600E: tall cell subtype $(P=0.004)$, many neoplastic cells $(>20 \%)$ with nuclear grooves $(P=0.0001)$ or with optically clear nuclei ( $>60 \% ; P=0.015)$, infiltrative tumor borders $(P=0.034)$, intraglandular tumor spread $(P=0.032)$, and a non-incidental discovery of the tumor $(P=0.010$; Table 5).

Table 6 summarizes tumor features, BRAF status and clinical data of the seven patients with unfavorable tumor-related events (persistent disease at 1year or recurrent disease). The BRAF status of tumors in patients with follow-up information is summarized in Table 7. Figure 3 shows the Kaplan-Meier curve of unfavorable tumor-related events among patients with a $B R A F$ V600E mutated or with a $B R A F$ wildtype microcarcinoma.

\section{Papillary Microcarcinoma Subtype and BRAF V600E}

The tall cell subtype showed the strongest link with BRAF V600E (Table 1; Figures 1a and 2a), and the association was independent of all other pathological and clinical variables tested (Tables 4 and 5). The classic subtype was also strongly associated with BRAF V600E (Figure 1a). The follicular variant subtype was inversely associated with $B R A F$ V600E (Figure 1a).

\section{Microscopic Papillary Microcarcinoma Features and BRAF V600E}

The microscopic appearance of BRAF V600E mutated cases was distinctive (Table 2, Figure 1b, Figures 2a to 2k).
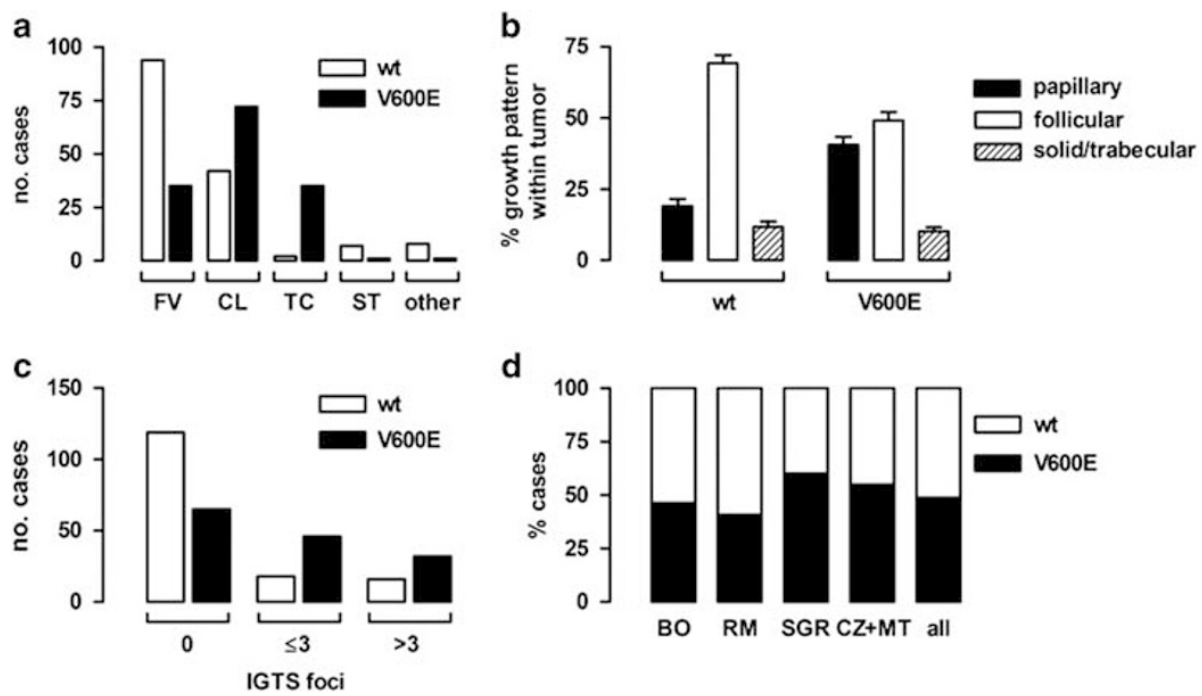

d

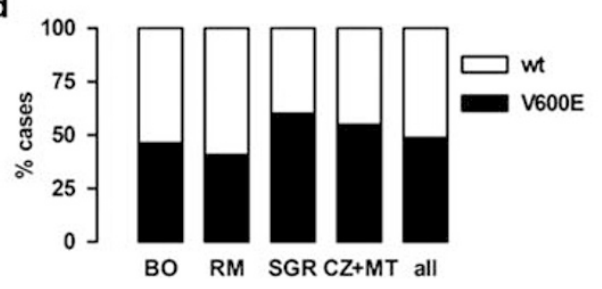

Figure 1 (a) Thyroid microcarcinoma subtype and BRAF status $(n=298)$ : CL, classic; FV, follicular variant; ST, solid trabecular; TC, tall cell. (b) Proportion of different growth patterns within the microcarcinoma and BRAF status $(n=298)$. (c) Intraglandular tumor spread (IGTS) and BRAF status $(n=298)$. (d) BRAF status of the microcarcinomas originating from different Italian regions $(n=298)$ : BO, Bologna (northern Italy); CZ+MT, Catanzaro and Matera (southern Italy); RM, Rome (central Italy); SGR, San Giovanni Rotondo (southern Italy). 

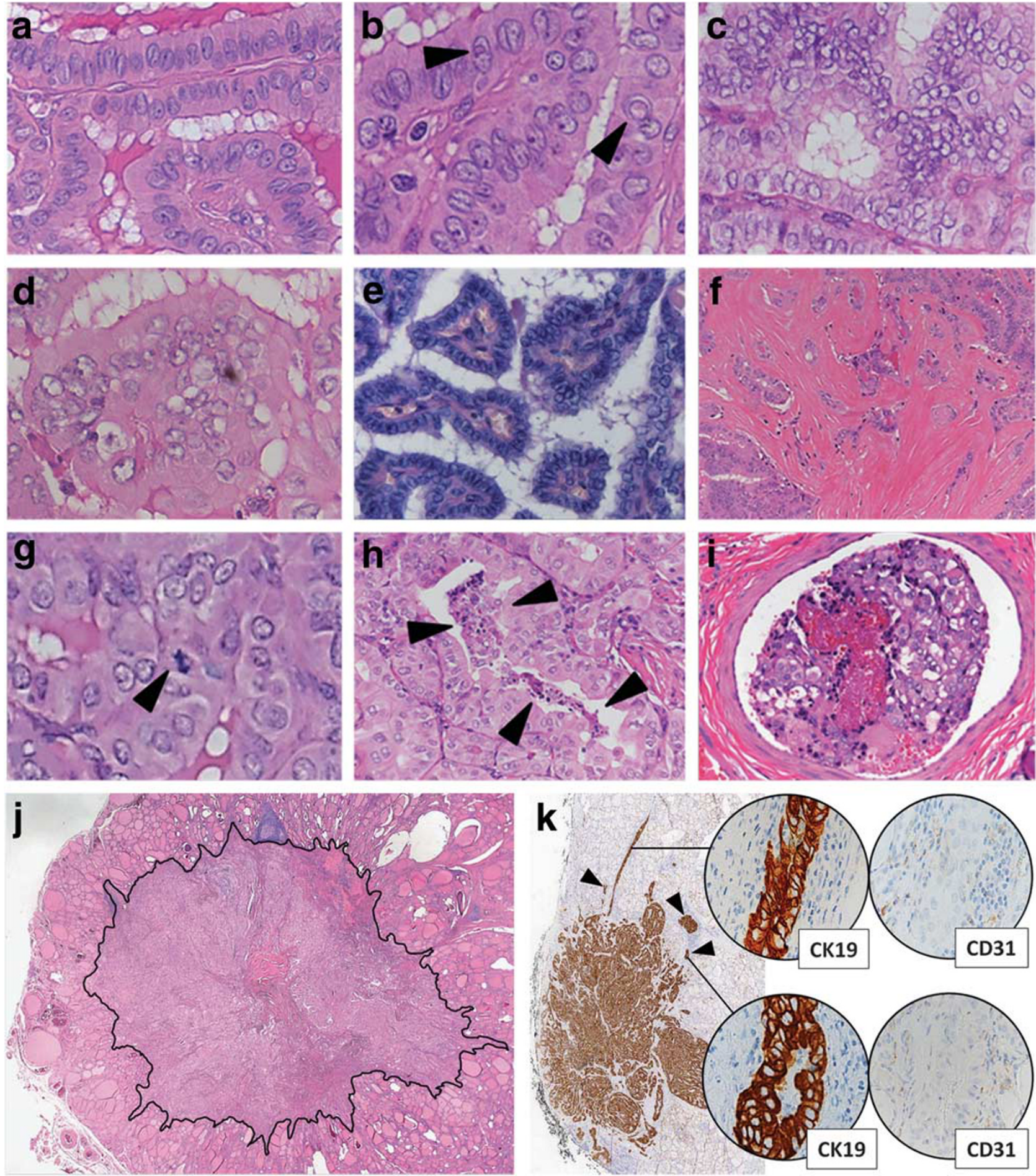

Figure 2 Histopathological features of microcarcinomas associated with the BRAF V600E mutation (Tables 2 and 3): (a) tall cells ( $\times 400)$. (b) Nuclear grooves and intranuclear inclusions (arrowheads; $\times 400)$. (c) Optically clear nuclei $(\times 400)$. (d) Eosinophilic cytoplasm $(\times 400)$. (e) Papillary growth $(\times 100)$. (f) Stromal fibrosis with desmoplasia (×40). (g) Mitoses (arrowhead; $\times 600)$. (h) Necrotic microfoci (arrowheads; $\times 200)$. (i) Vascular invasion $(\times 200)$. (j) Infiltrative growth pattern featuring a markedly irregular interface with non-neoplastic thyroid $(\times 20)$. (k) Intraglandular peritumoral spread (arrowheads) and elongated digitiform projections of neoplastic cells into non-neoplastic thyroid $(\times 20)$; immunohistochemical stain with cytokeratin 19 (CK19) highlights neoplastic cells $(\times 400)$; immunohistochemistry for the endothelial cell marker CD31 (CD31) does not demonstrate positive immunoreactivity around neoplastic cells $(\times 400)$, indicating that they are not growing into blood or lymphatic vascular channels. 
Table 5 Histopathological and clinical parameters associated to BRAF V600E $(P<0.1)$ after multivariate analyses in Tables $1-4$

\begin{tabular}{|c|c|c|}
\hline \multirow[b]{2}{*}{ Variables } & \multicolumn{2}{|l|}{ Multivariate logistic regression analysis } \\
\hline & OR $(95 \%$ CI $)$ & P-value \\
\hline \multicolumn{3}{|l|}{ Tumor subtype (Table 1) } \\
\hline Tall cell (vs other subtypes) & $20.89(2.66-163.66)$ & 0.004 \\
\hline \multicolumn{3}{|l|}{ Microscopic appearance of the tumor (Table 2) } \\
\hline Nuclear grooves & 4.18 (2.17-8.04; many/widespread vs few) & 0.0001 \\
\hline Optically clear nuclei & 2.41 (1.18-4.91; widespread vs few/many) & 0.015 \\
\hline \multicolumn{3}{|l|}{ Extent and type of tumor growth (Table 3) } \\
\hline $\begin{array}{l}\text { Tumor growth pattern at the border with the surrounding } \\
\text { non-neoplastic tissue }\end{array}$ & $\begin{array}{l}2.19 \text { (1.06-4.54; predominantly irregular/ } \\
\text { infiltrative vs smooth or partially infiltrative) }\end{array}$ & 0.034 \\
\hline Intraglandular tumor spread & 2.11 (1.07-4.18; present vs absent) & 0.032 \\
\hline \multicolumn{3}{|l|}{ Clinicopathological data (Table 4) } \\
\hline Microcarcinoma discovery & 2.68 (1.27-5.68; incidental vs not incidental) & 0.010 \\
\hline
\end{tabular}

Data based on 264 patients. Variables that were significantly correlated to each other after the Pearson test were excluded from the multivariate model.

Mutated tumors had a high proportion of tall cells, irrespective of the microcarcinoma subtype. The average proportion of tall cells (Figure 2a) in BRAF V600E mutated cases was $26 \%$ versus $2 \%$ in $B R A F$ wild-type cases (Table $2, P<0.0001$ ).

Other variables statistically associated with $B R A F$ V600E by univariate analysis were: nuclear features linked to classic papillary carcinoma morphology (chromatin clearing, nuclear membrane irregularities, grooves, and nuclear pseudoinclusions; Figures 2a to 2c); eosinophilic cytoplasm (Figure 2d), whereas cytoplasmic clearing was inversely related to the BRAF mutation; papillary pattern of growth (the average proportion of papillary growth in BRAF V600E-mutated microcarcinomas was $41 \%$ versus $19 \%$ in BRAF wild-type cases, $P<0.0001$, Table 2 , Figures $1 \mathrm{~b}$ and $2 \mathrm{e}$ ), whereas follicular growth was inversely related to the $B R A F$ mutation; tumor fibrosis with stromal desmoplasia (positive association; Figure 2f); lymphoid cell infiltration within the tumor and at the interface between the microcarcinoma and the surrounding non-neoplastic parenchyma (positive association; Table 2). Mitotic activity was present in 53 cases and 31 of them were BRAF V600E mutated (Table 2, $P=0.1136$; Figure 2g). Microscopic foci of necrosis were identified in seven microcarcinomas and six of the cases with necrosis were BRAF V600E mutated (Table 2, $P=0.0471$; Figure 2h).

Multivariate analysis showed that among the microscopic appearance variables considered in this study (Table 2) the presence within the microcarcinoma of many cells with nuclear grooves $(>20 \%)$ or optically clear nuclei $(>60 \%)$, the presence of $>50 \%$ tall cells, and of tumor-associated fibrosis were independently associated with BRAF V600E. The independence from other microscopic variables of lymphoid cell infiltration at the interface between the microcarcinoma and the surrounding non-neoplastic parenchyma was statistically borderline (Table 2, $P=0.051$ ).

\section{Extent and Type of Tumor Growth and BRAF V600E}

$B R A F$ V600E-mutated microcarcinomas were larger (5.9 versus $4.5 \mathrm{~mm}, P<0.0001$, Table 3 ) and were characterized by invasive features. Histological signs of blood vessel invasion were observed in 17 microcarcinomas and 14 of them were BRAF V600E mutated (Table 3, $P=0.0093$; Figure 2i). $B R A F$ V600E-mutated microcarcinomas had a predominantly infiltrative (as opposed to smooth and pushing) tumor border (Table 3, $P<0.0001$; Figure 2j). Typically, the interface between the microcarcinoma and the surrounding parenchyma was markedly irregular (Figure 2j), showing in some cases thin strings and elongated digitiform projections of neoplastic cells departing from the tumor and growing deeply into the surrounding tissue (Figure 2k). BRAF V600E-mutated microcarcinomas commonly infiltrated extrathyroidal tissue (Table $3, P<0.0001$ ).

Mutated tumors were associated with intraglandular tumor spread (Table 3, $P<0.0001$; Figure 2k). Most of the foci of intraglandular neoplastic cell spread were microscopic and located within a $5 \mathrm{~mm}$ radius of the outer border of the microcarcinoma (in 92 of 112 microcarcinomas with intraglandular tumor spread, $82 \%$, Figure 2k). Immunohistochemical analysis of 14 $B R A F$ V600E-mutated microcarcinomas with intraglandular tumor spread for the papillary carcinoma marker cytokeratin 19, endothelial markers (CD31 and CD34) and lymphatic endothelial cells (Podoplanin, D2-40 antibody) did not demonstrate positive immunoreactivity around the foci of intraglandular neoplastic cell dissemination, suggesting that they are not the result of permeation of blood vessels or lymphatic vascular channels (Figure 2k). 
Table 6 Clinicopathological features and BRAF status in the seven patients with unfavorable tumor-related events

\begin{tabular}{|c|c|c|c|c|c|c|c|}
\hline Features & Case 1 & Case 2 & Case 3 & Case 4 & Case 5 & Case 6 & Case 7 \\
\hline Age & 59 & 40 & 46 & 16 & 29 & 65 & 48 \\
\hline Sex & $\mathrm{F}$ & M & $\mathrm{F}$ & $\mathrm{F}$ & $\mathrm{F}$ & $\mathrm{M}$ & $\mathrm{F}$ \\
\hline $\begin{array}{l}\text { Microcarcinoma discovered } \\
\text { incidentally }\end{array}$ & Yes & Yes & Yes & $\begin{array}{l}\text { No (LN metastases at } \\
\text { presentation) }\end{array}$ & $\begin{array}{l}\text { No (LN metastases at } \\
\text { presentation) }\end{array}$ & $\begin{array}{l}\text { No (LN metastases at } \\
\text { presentation) }\end{array}$ & $\begin{array}{l}\text { No (LN metastases at } \\
\text { presentation) }\end{array}$ \\
\hline Microcarcinoma subtype & TC & ST & CL & CL & CL & TC & TC \\
\hline Tumor size (mm) & 3.6 & 8.5 & 10.0 & 10.0 & 7.3 & 8.0 & 9.0 \\
\hline Intraglandular tumor spread & Yes $(\leq 3$ foci $)$ & Yes $(\leq 3$ foci $)$ & Yes $(\leq 3$ foci $)$ & Yes (>3 foci) & Yes $(>3$ foci) & Yes ( $>3$ foci) & Yes ( $>3$ foci) \\
\hline Multicentricity & No & Yes & No & No & No & No & No \\
\hline Extrathyroidal extension & No & No & Yes (C) & Yes (C) & Yes (M) & Yes (C) & Yes (C) \\
\hline Stage at diagnosis (pTNM) & 1 (pT1a No Mx) & $1 \underset{\mathrm{Mx})}{(\mathrm{pT} 1 \mathrm{am}} \mathrm{Nx}$ & $\begin{array}{l}3 \text { (pT3 Nx } \\
\text { Mx) }\end{array}$ & 1 (pT3 N1b Mx) & 1 (pT3 N1b Mx) & 4a (pT3 N1b Mx) & 4a (pT3 N1b Mx) \\
\hline Surgery (type) & $\mathrm{TT}$ & TT & $\mathrm{TT}$ & TT; central, lateral LND & TT; central, lateral LND & TT; central, lateral LND & TT; central, lateral LND \\
\hline Surgical margin & Negative & Negative & Positive & Negative & Positive & Negative & Negative \\
\hline American Thyroid & 0 & 0 & 1 & 1 & 1 & 1 & 1 \\
\hline \multicolumn{8}{|l|}{$\begin{array}{l}\text { Association recurrence risk } \\
\text { group }\end{array}$} \\
\hline 1st year FU visit & BIR & SIR & SIR & SIR & SIR & SIR & ER \\
\hline Persistent disease site & NA & Lateral neck & Lateral neck & Lung & Lateral neck & Mediastinum & NA \\
\hline Recurrent disease & Yes & UNK & NA & $\mathrm{NA}$ & NA & NA & Yes \\
\hline Site of recurrence & Mediastinum & UNK & NA & NA & NA & NA & Lateral neck \\
\hline $\begin{array}{l}\text { Recurrence time (months from } \\
\text { initial diagnosis) }\end{array}$ & 57 & UNK & NA & NA & NA & NA & 16 \\
\hline Additional therapy & RAI & UNK & Surgery, RAI & RAI & No & Surgery, RAI & No \\
\hline Status of last FU & ER & SIR & ER & $\mathrm{ER}$ & SIR & ER & SIR \\
\hline FU total (months) & 156 & 12 & 68 & 90 & 95 & 44 & 19 \\
\hline BRAF status & V600E & WT & V600E & WT & V600E & V600E & V600E \\
\hline
\end{tabular}

Abbreviations: BIR, biochemical incomplete response (abnormal thyroglobulin values); C, conspicuous extrathyroidal extension: $>1$ submillimetric focus of tumor or a single focus $\geq 1$ millimeter in the extrathyroidal tissues; CL, classic microcarcinoma; ER, excellent response (no biochemical, structural or clinical evidence of disease); FU, follow up; LN, lymph node; LND, lymph node

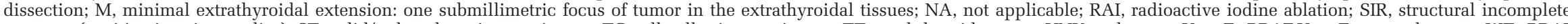

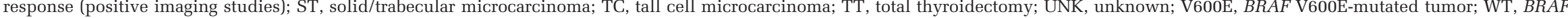
wild-type tumor.

Data from 191 patients with follow-up information. 
Table 7 Disease-related events and $B R A F$ status

\begin{tabular}{lcccc}
\hline & \multicolumn{2}{c}{ BRAF } & & $\begin{array}{c}\text { Univariate } \\
\text { analysis }\end{array}$ \\
\cline { 2 - 3 } $\begin{array}{l}\text { Follow-up } \\
\text { information }\end{array}$ & V600E (\%) & WT (\%) & P-value \\
\hline $\begin{array}{l}\text { Persistent Disease } \\
\text { No }(n=186)\end{array}$ & $89 / 92(97)$ & $97 / 99(98)$ & 0.5916 \\
$\quad$ Yes $(n=5)$ & $3 / 92(3)$ & $2 / 99(2)$ & \\
Recurrent Disease & & & \\
$\quad$ No $(n=188)$ & $90 / 92(98)$ & $98 / 98$ & \\
Yes $(n=2)$ & $2 / 92(2)$ & $0 / 98(0)$ & \\
Disease at last follow-up & & \\
$\quad$ No $(n=188)$ & $90 / 92(98)$ & $98 / 99(99)$ & 0.1423 \\
$\quad$ Yes $(n=3)$ & $2 / 92(2)$ & $1 / 99(1)$ & \\
\hline
\end{tabular}

Abbreviations: V600E, BRAF V600E-mutated tumors; WT, BRAF wild-type tumors. Data from 191 patients with follow-up information.

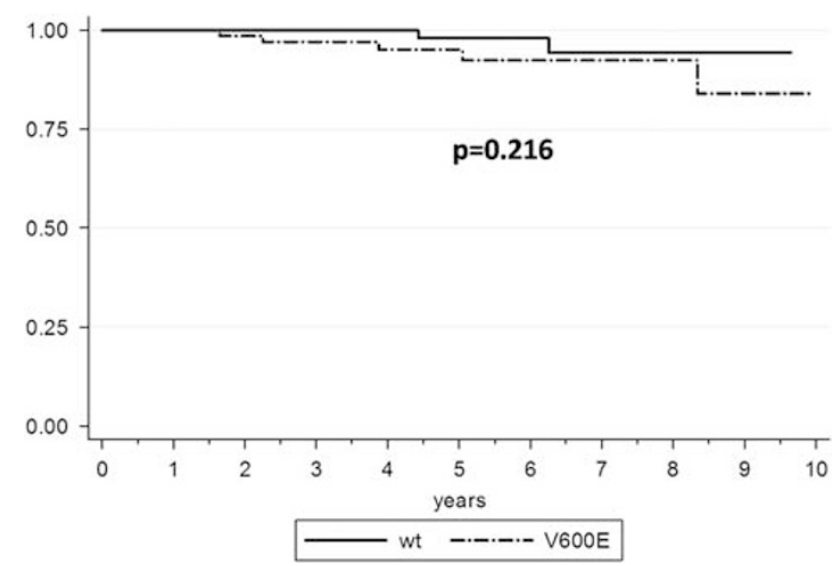

Figure 3 Kaplan-Meier curve of patients with unfavorable tumorrelated events (persistent disease at 1 year, recurrent disease, alive with disease at last follow-up; $n=7,5 B R A F$ V600E mutated tumors, $2 B R A F$ wild type tumors). Data from 191 patients with follow-up information.

Although BRAF V600E was linked to mutifocality resulting from intraglandular tumor spread, in this series BRAF V600E did not correlate with tumor multicentricity (Table 3, $P=0.6090$ ). Microcarcinomas that developed within a larger hyperplastic nodule were infrequently $B R A F$ V600E mutated (Table 3, $P=0.004$ ).

Among the variables considered in Table 3, multivariate analysis showed that intraglandular tumor spread, infiltrative tumor borders and extension into extrathyroidal tissues were independently associated with the BRAF V600E mutation. The independence from the other Table 3 variables of the lack of $B R A F$ V600E mutation for papillary microcarcinomas that developed within a hyperplastic nodule was statistically borderline (Table $3, P=0.078$ ).

\section{Clinicopathological Data, Follow-up Status and BRAF} V600E

Univariate analysis showed that patients with $B R A F$ V600E-mutated tumors were younger than those with tumors lacking the mutation (48 versus 51 years of age, Table 4, $P=0.0470$ ). Microcarcinomas with the BRAF V600E mutation were less frequently diagnosed as an incidental finding (Table 4, $P<0.0001$ ), were more commonly of higher stage (Table $4, P=0.0179$ ), more often had metastases to cervical nodes (Table 4, $P=0.0333$ ), and these lymph node metastases tended to more frequently involve both central compartment as well as lateral cervical nodes (Table 4, $P=0.0438$ ). Patients with $B R A F$ V600E-mutated tumors more commonly belonged to an intermediate as opposed to a low American Thyroid Association recurrence risk group (Table 4, $P<0.0001)$. Not only BRAF V600E-mutated microcarcinomas rarely developed within hyperplastic nodules (see above, Extent and Type of Tumor Growth and BRAF V600E), they were also less common in glands affected by multinodular hyperplasia (Table 4, $P=0.0128$ ). We observed an inverse relationship between BRAF V600E-mutated microcarcinomas and the occurrence of diffuse lymphocytic thyroiditis (Table $4, P=0.0489$ ).

Among the variables considered in Table 4, multivariate analysis showed that non-incidental tumor discovery and intermediate (as opposed to low) American Thyroid Association recurrence risk group were independently associated with the BRAF V600E mutation.

One hundred and ninety-one patients had adequate follow-up information. No patient died of or with disease. Seven experienced unfavorable events related to the microcarcinoma at follow-up: five had persistent disease and two recurrent disease (Tables 6 and 7). Five of the seven patients with unfavorable tumor-related events had $B R A F$ V600Emutated microcarcinomas (Table 4, $P=0.2095$; Figure 3). Of the five patients with persistent disease three carried $B R A F$ V600E-mutated tumors $(3 \%$ of the 92 patients with BRAF V600E-mutated microcarcinomas; Table 7). Both patients with recurrent disease carried BRAF V600E-mutated tumors $(2 \%$ of the 92 patients with BRAF V600E-mutated microcarcinomas; Table 7).

\section{Discussion}

A major finding of the study is the close correlation between BRAF V600E and specific microscopic features of the tumor. The strongest association is with microcarcinomas subtyped as tall cell variant, confirming that the link noted for larger tumors is also true for microcarcinomas. ${ }^{10,29}$ In our series nearly $95 \%$ of microcarcinomas subtyped as tall cell are BRAF V600E mutated, and the correlation is independent of all other parameters tested after multivariate analysis. Interestingly, BRAF V600E is 
also associated with specific microscopic neoplastic cell features, irrespective of microcarcinoma subtype, to the point that after the study it became easy for the pathologists who reviewed the cases to correctly guess the presence of the mutation in a given microcarcinoma. Being 'miniature' lesions, microcarcinomas sometimes display alterations of nuclear morphology that are less developed when compared with those found in larger tumors and tend to have a relative predominance of follicular growth patterns. ${ }^{30}$ In our series, BRAF V600E positive microcarcinomas show full development of alterations of nuclear morphology that typically define papillary carcinoma (eg chromatin clearing, nuclear grooves etc), and have significantly higher proportions of papillary growth, compared with $B R A F$ wild-type cases. We measured the proportion of tall cells within each microcarcinoma and found it to be $>10$ times higher in BRAF V600E mutated cases than in BRAF wild-type tumors $(26 \%$ versus $2 \%$ ). Remarkably, this proportion of tall cells is close to the $30 \%$ tall cell cut-off that has been associated with the prognostic features of tall cell variant papillary thyroid carcinoma in larger tumors. ${ }^{31}$

The strong similarity of microscopic features between BRAF V600E-mutated microcarcinomas and BRAF V600E-mutated carcinomas $>1 \mathrm{~cm}$ supports the hypothesis that they belong biologically to the same class, and that the mutation induces the same set of morphologic alterations, independent of tumor size. A corollary to this hypothesis is that $B R A F$ V600E-mutated microcarcinomas represent indeed low stage lesions, with the potential to evolve into larger clinically evident tumors. In our series we find mitotic activity in a small minority of microcarcinomas, and in rare cases microscopic foci of necrosis, both distinctive features of high-grade neoplasms that are usually large and poorly differentiated. Both mitotic activity and necrosis are more common in BRAF V600E-mutated tumors, further supporting the contention that this mutation confers to the tumor a potential to progress.

A second set of important findings is the correlation between BRAF V600E and aggressive growth features. In our series, mutated cases are statistically associated with larger tumor size. Such a correlation has been demonstrated in a few other microcarcinoma studies. ${ }^{17,32}$ The most striking observation is that BRAF V600E-mutated microcarcinomas have distinctively invasive features. Their growth is almost 'weed-like', with a very infiltrative tumor border, sometimes characterized by thin strings and digitiform projections of neoplastic cells penetrating into the parenchyma surrounding the tumor. BRAF V600E-mutated microcarcinomas also show a strong tendency to spread. We defined intraglandular tumor spread as satellite neoplastic cell aggregates separated from the microcarcinoma by non-neoplastic thyroid and showing its same morphologic appearance. The large majority of these aggregates are of microscopic size and located within a $5 \mathrm{~mm}$ radius of the tumor. By immunohistochemical analysis of intraglandular tumor spread foci using vascular and lymphatic endothelial cell markers we find no evidence that they represent invasion of vascular spaces. It is likely that at least some of these microscopic peritumoral neoplastic foci are cross sections of the digitiform projections that emanate from the tumor. Although BRAF V600E mutation is linked to mutifocality resulting from tumor dissemination (intraglandular tumor spread), we do not observe a correlation with tumor multicentricity. Lack of correlation between BRAF V600E and microcarcinoma multicentricity has been reported in other studies, ${ }^{16,19,32}$ supporting the hypothesis that a significant proportion of multicentric microcarcinomas likely represent synchronous lesions of independent origin. ${ }^{33-35}$ Blood vessel invasion is very uncommon in microcarcinomas and has not been previously associated with $B R A F$ V600E. Other studies have indicated that BRAF V600E-mutated microcarcinomas often extend into extrathyroidal tissue. ${ }^{16,17,19} \mathrm{~A}$ few have also shown that they tend to have infiltrative borders, ${ }^{19,36}$ and to spread within the gland. ${ }^{36}$ In our series infiltrative growth and intraglandular tumor spread show a strong and independent link to BRAF V600E, and emerge among the most distinctive features associated with the mutation.

We find a statistical association between $B R A F$ V600E and lymph node metastases at presentation, confirming what has been reported in other series from single institutions. ${ }^{16,32}$ In addition we demonstrate that BRAF V600E is also statistically linked to more extensive nodal disease, that in $B R A F$-mutated microcarcinomas tends to involve not only central compartment but also lateral cervical lymph nodes. ${ }^{19}$

In our series the mean age of the patients with $B R A F$ V600E-mutated tumors is statistically lower compared with that of patients whose tumors are wild type. BRAF V600E has been linked to older age in tumors $>1 \mathrm{~cm},{ }^{10}$ but in some microcarcinoma series the same correlation between young age and $B R A F$ V600E has emerged. ${ }^{16}$ At variance with what happens for papillary carcinomas $>1 \mathrm{~cm}$, young, as opposed to older age is associated with tumor recurrence, ${ }^{7}$ and one observational study from Japan has identified young age as an independent factor predicting microcarcinoma progression. ${ }^{37}$

In this study the large majority of microcarcinomas discovered incidentally lack $B R A F$ V600E. We are aware of only one study ${ }^{18}$ that has specifically addressed this issue, reporting a similar inverse relationship between the incidental discovery of the tumor and the mutation. We not only confirm the observation, but also demonstrate that the link between incidental microcarcinoma discovery and a lack of $B R A F$ V600E is very firm and independent of all other factors tested after multivariate analysis. Latent papillary microcarcinomas discovered incidentally likely include that subset of tumors of very 
low malignant potential found in autopsy series. ${ }^{1}$ A large meta-analysis of thyroid microcarcinomas has shown that patients with incidentally discovered tumors experience fewer recurrences inspite of receiving more limited treatment, independently of other clinicopathological factors, suggesting that non-incidental thyroid microcarcinomas are biologically different, with more aggressive, therapyresistant features. ${ }^{38}$

We show that BRAF V600E-mutated microcarcinomas are statistically associated with a higher risk of recurrence according to the 2009 American Thyroid Association criteria, and that the mutation correlates with those variables (multifocality consistent with intraglandular tumor dissemination, lymph node metastases, younger age of the patient, and a non-incidental discovery of the tumor) specifically linked to tumor recurrence in microcarcinoma. ${ }^{7}$ Few patients in this series had recurrent or persistent disease, but the majority of them harbored BRAF V600E positive tumors. The proportion of our patients with BRAF V600E-mutated papillary microcarcinomas that experienced disease persistence $(3 \%)$ or recurrence $(2 \%)$ is in the same range of the rate for persistent or recurrent disease $(7 \%$ and $1 \%$, respectively) recently reported in a large series of clinically evident papillary carcinomas. ${ }^{39}$ Furthermore, a meta-analysis has recently shown that the mutation is associated with papillary carcinoma recurrence even in low stage tumors and microcarcinomas. ${ }^{12}$

Remarkably, the correlation between BRAF V600E and unfavorable microcarcinoma characteristics is confirmed after excluding from the statistical analysis cases subtyped as follicular variant, a subtype that is generally regarded as particularly indolent among papillary carcinomas $>1 \mathrm{~cm}$ : tall cell subtype, tumor size $>5 \mathrm{~mm}$, infiltrative growth, extrathyroidal extension, higher risk of recurrence (American Thyroid Association, 2009), and a nonincidental discovery of the microcarcinoma were still strongly linked to BRAF V600E $(P<0.05$; data not shown).

Observational studies carried out in Japan, where selected patients with microcarcinomas are managed conservatively and followed rather than treated up front, ${ }^{40,41}$ are showing that only $\sim 15 \%$ of microcarcinomas increase in size after an average followup of 10 years. New lymph node metastases were found in $3 \%$ of 340 patients after 10 years of observation. ${ }^{40}$ If we assume that the prevalence of $B R A F$ V600E in microcarcinoma in Japan is $~ 30 \%{ }^{22}$ one would have expected a larger proportion of tumors showing signs of progression. The discrepancy between the findings of this and other series showing that BRAF V600E-mutated microcarcinomas are endowed with worrisome features and the results of these observational studies is puzzling. It may be explained if we consider BRAF V600E as a 'sensitive', but by no means 'specific' marker to identify those microcarcinomas that, if untreated, will eventually evolve. Additional molecular alterations must be involved in this progression. This is supported by recent data emerging from the work of The Cancer Genome Atlas project, indicating that BRAF V600E-mutated papillary carcinoma is indeed a rather heterogeneous group of tumors with several molecular subtypes. ${ }^{42}$

To the best of our knowledge this is the first multicenter study to address in detail the microscopic, pathologic, and clinical aspects of $B R A F$ V600E-mutated microcarcinomas. On the whole, our data confirm that thyroid microcarcinomas are heterogeneous and that it is inaccurate and misleading to consider them as a single category harboring the same hazard for the patient. BRAF V600E is consistently associated with those conventional clinico-pathological features known to be adverse prognostic factors for microcarcinomas, and may therefore be rightfully considered a surrogate marker for increased clinical risk. A major contribution of $B R A F$ testing to risk stratification would be to identify those tumors ( $B R A F$ wild type) that can be regarded as indolent, with a very low chance of recurrence, to be managed conservatively. As the large majority of patients with mutated tumors do not experience significant disease-related events additional factors that promote progression of BRAF V600E-mutated microcarcinomas should be investigated.

\section{Acknowledgments}

This work was supported in part by an Italian Government MURST grant (20093XZC57_003) to GT. We are grateful to the Italian Thyroid Cancer Observatory (ITCO) Foundation for its support of CD, LL, RB, GC, DM, MT, AV, GR and SF.

\section{Disclosure/conflict of interest}

The authors declare no conflict of interest.

\section{References}

1 Lee YS, Lim H, Chang HS et al. Papillary thyroid microcarcinomas are different from latent papillary thyroid carcinomas at autopsy. J Korean Med Sci 2014;29:676-679.

2 Hay ID, Hutchinson ME, Gonzalez-Losada $\mathrm{T}$ et al. Papillary thyroid microcarcinoma: a study of 900 cases observed in a 60-year period. Surgery 2008;144: 980-987. discussion 987-988.

3 Cohen MS, Arslan N, Dehdashti F et al. Risk of malignancy in thyroid incidentalomas identified by fluorodeoxyglucose-positron emission tomography. Surgery 2001;130:941-946.

4 Enewold L, Zhu K, Ron E et al. Rising thyroid cancer incidence in the United States by demographic and tumor characteristics, 1980-2005. Cancer Epidemiol Biomarkers Prev 2009;18:784-791. 
5 Rosai J, LiVolsi VA, Sobrinho-Simoes M et al. Renaming papillary microcarcinoma of the thyroid gland: the Porto proposal. Int J Surg Pathol 2003;11:249-251.

6 Durante C, Attard M, Torlontano M et al. Identification and optimal postsurgical follow-up of patients with very low-risk papillary thyroid microcarcinomas. J Clin Endocrinol Metab 2010;95:4882-4888.

7 Roti E, degli Uberti EC, Bondanelli M et al. Thyroid papillary microcarcinoma: a descriptive and metaanalysis study. Eur J Endocrinol 2008;159:659-673.

8 Ghossein R, Ganly I, Biagini et al. Prognostic factors in papillary microcarcinoma with emphasis on histologic subtyping: a clinicopathologic study of 148 cases. Thyroid 2014;24:245-253.

9 Piana S, Ragazzi M, Tallini G et al. Papillary thyroid microcarcinoma with fatal outcome: evidence of tumor progression in lymph node metastases: report of 3 cases, with morphological and molecular analysis. Hum Pathol 2013;44:556-565.

10 Xing M. BRAF mutation in papillary thyroid cancer: pathogenic role, molecular bases, and clinical implications. Endocr Rev 2007;28:742-762.

11 Xing M, Alzahrani AS, Carson KA et al. Association between BRAF V600E mutation and mortality in patients with papillary thyroid cancer. JAMA 2013;309: 1493-1501.

12 Xing M, Alzahrani AS, Carson KA et al. Association Between BRAF V600E Mutation and Recurrence of Papillary Thyroid Cancer. J Clin Oncol 2014;33: 42-50.

13 Durante C, Puxeddu E, Ferretti E et al. BRAF mutations in papillary thyroid carcinomas inhibit genes involved in iodine metabolism. J Clin Endocrinol Metab 2007;92: 2840-2843.

14 Franzoni A, Dima M, D'Agostino M et al. Prohibitin is overexpressed in papillary thyroid carcinomas bearing the BRAF(V600E) mutation. Thyroid 2009;19:247-255.

15 Puxeddu E, Durante C, Avenia N et al. Clinical implications of BRAF mutation in thyroid carcinoma. Trends Endocrinol Metab 2008;19:138-145.

16 Basolo F, Torregrossa L, Giannini R et al. Correlation between the BRAF V600E mutation and tumor invasiveness in papillary thyroid carcinomas smaller than 20 millimeters: analysis of 1060 cases. J Clin Endocrinol Metab 2010;95:4197-4205.

17 Kwak JY, Kim EK, Chung WY et al. Association of BRAFV600E mutation with poor clinical prognostic factors and US features in Korean patients with papillary thyroid microcarcinoma. Radiology 2009;253: 854-860.

18 Ugolini C, Giannini R, Lupi C et al. Presence of BRAF V600E in very early stages of papillary thyroid carcinoma. Thyroid 2007;17:381-388.

19 Virk RK, Van Dyke AL, Finkelstein et al. BRAFV600E mutation in papillary thyroid microcarcinoma: a genotype-phenotype correlation. Mod Pathol 2013;26: 62-70.

20 Elisei R, Viola D, Torregrossa L et al. The BRAF(V600E) mutation is an independent, poor prognostic factor for the outcome of patients with low-risk intrathyroid papillary thyroid carcinoma: single-institution results from a large cohort study. J Clin Endocrinol Metab 2012;97:4390-4398.

21 Choi SY, Park H, Kang MK et al. The relationship between the BRAF(V600E) mutation in papillary thyroid microcarcinoma and clinicopathologic factors. World J Surg Oncol 2013;11:291.
22 Ito $\mathrm{Y}$, Yoshida $\mathrm{H}$, Maruo $\mathrm{R}$ et al. BRAF mutation in papillary thyroid carcinoma in a Japanese population: its lack of correlation with high-risk clinicopathological features and disease-free survival of patients. Endocr J 2009;56:89-97.

23 Trovisco V, Soares P, Preto et al. Type and prevalence of BRAF mutations are closely associated with papillary thyroid carcinoma histotype and patients' age but not with tumour aggressiveness. Virchows Arch 2005;446:589-595.

24 Walczyk A, Kowalska A, Kowalik et al. The BRAF (V600E) mutation in papillary thyroid microcarcinoma: does the mutation have an impact on clinical outcome? Clin Endocrinol (Oxf) 2014;80:899-904.

25 Puxeddu E, Filetti S. BRAF mutation assessment in papillary thyroid cancer: are we ready to use it in clinical practice? Endocrine 2014;45:341-343.

26 Soares P, Sobrinho-Simoes M. Cancer: Small papillary thyroid cancers-is BRAF of prognostic value? Nat Rev Endocrinol 2011;7:9-10.

27 Morandi L, de Biase D, Visani M et al. Allele specific locked nucleic acid quantitative PCR (ASLNAqPCR): an accurate and cost-effective assay to diagnose and quantify KRAS and BRAF mutation. PLoS One 2012;7: e36084.

28 Durante C, Tallini G, Puxeddu E et al. BRAF(V600E) mutation and expression of proangiogenic molecular markers in papillary thyroid carcinomas. Eur J Endocrinol 2011;165:455-463.

29 Adeniran AJ, Zhu Z, Gandhi $\mathrm{M}$ et al. Correlation between genetic alterations and microscopic features, clinical manifestations, and prognostic characteristics of thyroid papillary carcinomas. Am J Surg Pathol 2006;30:216-222.

30 Baloch ZW, LiVolsi VA. Microcarcinoma of the thyroid. Adv Anat Pathol 2006;13:69-75.

31 Ganly I, Ibrahimpasic T, Rivera M et al. Prognostic implications of papillary thyroid carcinoma with tallcell features. Thyroid 2014;24:662-670.

32 Zheng X, Wei S, Han Y et al. Papillary microcarcinoma of the thyroid: clinical characteristics and BRAF (V600E) mutational status of 977 cases. Ann Surg Oncol 2013;20:2266-2273.

33 Bansal M, Gandhi M, Ferris RL et al. Molecular and histopathologic characteristics of multifocal papillary thyroid carcinoma. Am J Surg Pathol 2013;37: 1586-1591.

34 Kuhn E, Teller L, Piana S et al. Different clonal origin of bilateral papillary thyroid carcinoma, with a review of the literature. Endocr Pathol 2012;23: 101-107.

35 Sugg SL, Ezzat S, Rosen IB et al. Distinct multiple RET/ PTC gene rearrangements in multifocal papillary thyroid neoplasia. J Clin Endocrinol Metab 1998;83: 4116-4122.

36 Niemeier LA, Kuffner Akatsu H, Song C et al. A combined molecular-pathologic score improves risk stratification of thyroid papillary microcarcinoma. Cancer 2012;118:2069-2077.

37 Ito Y, Miyauchi A, Kihara $\mathrm{M}$ et al. Patient age is significantly related to the progression of papillary microcarcinoma of the thyroid under observation. Thyroid 2014;24:27-34.

38 Mehanna H, Al-Maqbili T, Carter B et al. Differences in the recurrence and mortality outcomes rates of incidental and nonincidental papillary thyroid microcarcinoma: a systematic review and meta-analysis of 21329 
person-years of follow-up. J Clin Endocrinol Metab 2014;99:2834-2843.

39 Durante C, Montesano T, Torlontano M et al. Papillary thyroid cancer: time course of recurrences during postsurgery surveillance. J Clin Endocrinol Metab 2013;98:636-642.

40 Ito Y, Miyauchi A, Inoue $\mathrm{H}$ et al. An observational trial for papillary thyroid microcarcinoma in Japanese patients. World J Surg 2010;34:28-35.
41 Sugitani I, Toda K, Yamada K et al. Three distinctly different kinds of papillary thyroid microcarcinoma should be recognized: our treatment strategies and outcomes. World J Surg 2010;34: 1222-1231.

42 Cancer Genome Atlas Research Network Electronic address gue, Cancer Genome Atlas Research N. Integrated genomic characterization of papillary thyroid carcinoma. Cell 2014;159:676-690.

Supplementary Information accompanies the paper on Modern Pathology website (http://www.nature.com/ modpathol). 